\title{
PENINGKATAN KEMANDIRIAN BELAJAR MATEMATIKA SISWA SMP MELALUI MODEL LEARNING CYCLE 5E DENGAN TEKNIK METAKOGNITIF
}

\author{
Runisah \\ Universitas Wiralodra, Jl. Ir. H. Djuanda Km 3 Indramayu, Jawa Barat \\ runisah_69@yahoo.co.id
}

\begin{abstract}
ABSTRAK
Penelitian ini bertujuan untuk menggambarkan pencapaian dan peningkatan kemandirian belajar siswa dalam matematika sebagai dampak penggunaan model Learning Cycle $5 E$ dengan Teknik Metakognitif (LCT), Learning Cycle $5 E$ (LC), dan pembelajaran Konvensional $(\mathrm{KV})$. Populasi dalam penelitian ini adalah siswa SMP di Indramayu, Indonesia. Sampel berjumlah 173 siswa kelas VIII yang mewakili satu sekolah level tinggi dan satu sekolah level sedang. Penelitian ini merupakan penelitian kuasi eksperimen dengan desain kelompok kontrol pretes-postes. Instrumen yang digunakan berupa skala kemandirian belajar siswa dan lembar observasi. Dari hasil penelitian disimpulkan: 1) Berdasarkan keseluruhan siswa, tidak terdapat perbedaan pencapaian dan peningkatan kemandirian belajar antara kelompok LCT dan LC, namun pencapaian dan peningkatan kemandirian belajar kelompok LCT dan LC lebih baik dari kelompok KV; 2) Terdapat pengaruh interaksi antara model pembelajaran (LCT, LC, dan KV) dan level sekolah (tinggi, sedang) terhadap peningkatan kemandirian belajar.
\end{abstract}

Kata Kunci: kemandirian belajar, Learning Cycle 5E, matematika, teknik metakognitif

\section{ABSTRACT}

The purposes of this study are to describe enhancement and achievement of students'Self Regulated Learning (SRL) in mathematics as a result of the 5E Learning Cycle with Metacognitive Technique (LCT), the 5E Learning Cycle (LC) and Conventional Learning (KV) implementation. The population of this study is junior high school students in Indramayu city, Indonesia. The sample is eight grade students which amounts to 173 from two school levels classified as high and medium level. This study use quasi experimental method with pretest-posttest control group design. Instruments are SRL scale and observation sheet. The study reveal that 1) In the term of overall, there is no difference of SRL achievement and enhancement between LCT and LC group, however SRL achievement and enhancement of LCT and LC group is better than KV group; 2) There is interaction effect between learning model (LCT, LC, KV) and school level (high and medium level toward enhancement of students'SRL

Key word: Self Regulated Learning, 5E Learning Cycle, Mathematics, Metacognitive Technique 


\section{PENDAHULUAN}

Kemandirian belajar merupakan salah satu aspek yang sangat penting untuk dikembangkan pada siswa. Hal tersebut dikarenakan kemandirian belajar merupakan aspek yang menentukan keberhasilan dalam belajar. Hal tersebut sejalan dengan penjelasan Yang (dalam Hargis, 2000) bahwa individu yang memiliki kemandirian belajar yang tinggi mempunyai kecenderungan untuk belajar lebih baik, mempunyai kemampuan dalam melakukan pemantauan, pengevaluasian dan pengaturan belajarnya, serta mengatur waktu secara lebih efisien.

Pengembangan kemandirian belajar siswa dapat dilakukan melalui pembelajaran matematika. Kemandirian belajar dalam matematika yang dikembangkan di sekolah selain menentukan keberhasilan belajar, juga menjadi modal utama untuk menjadi seorang yang mandiri dalam kehidupan seharihari. Kemandirian yang dimiliki siswa sangat diperlukan sebagai bekal dalam menghadapi berbagai perubahan atau permasalahan yang terjadi sebagai dampak adanya kemajuan ilmu pengetahuan dan teknologi.

Meskipun kemandirian belajar penting untuk dikembangkan, namun pada umumnya siswa masih memiliki kemandirian belajar yang rendah. Dari hasil studi yang dilakukan Runisah (2015) yang melibatkan 150 orang siswa kelas VIII dapat disimpulkan bahwa kemandirian belajar dalam matematika masih rendah. Skor ratarata siswa hanya mencapai 112 dari skor maksimal ideal 200.

Salah satu pemicu rendahnya kemandirian belajar yaitu proses pembelajaran yang dilakukan. Hal ini diungkapkan Munandar (2012) bahwa penekanan dalam bidang pendidikan lebih pada hafalan dan mencari satu jawaban yang benar terhadap soal-soal yang diberikan. Penekanan pada hafalan menjadikan siswa kurang dilibatkan dalam proses berpikir untuk mengembangkan ide-idenya. Artinya penekanan pembelajaran belum mengembangkan kemandirian belajar secara optimal. Hal ini sejalan dengan pendapat Darr \& Fisher (2004) yang mengungkapkan bahwa apabila siswa diharapkan menjadi siswa yang mandiri, mereka perlu aktif dan dihadapkan pada kesempatankesempatan yang memungkinkan mereka berpikir, mengamati, dan mengikuti pikiran orang lain. Oleh karena itu diperlukan model pembelajaran yang menjadikan siswa lebih mandiri.

Salah satu model pembelajaran yang berpotensi untuk meningkatkan kemandirian belajar yaitu model Learning Cycle 5E. Learning Cycle 5E merupakan suatu pembelajaran berbasis konstruktivisme. Menurut Bybee, Taylor, Gardner, Scotter, Powel, Westbrook, \& Landes (2006) Learning Cycle 5E memiliki lima tahap yaitu engage, explore, explain, elaborate, dan evaluate. Pada tahap engage, guru membantu siswa agar terlibat dalam pembelajaran. Pada tahap explore, siswa dilibatkan dalam eksplorasi untuk menghasilkan ideide baru. Hasil eksplorasi tersebut dijelaskan pada tahap explain oleh siswa. Selanjutnya pemahaman serta kemampuan siswa diperluas pada tahap elaborate. Tahap terakhir yaitu evaluate, pada tahap ini dilakukan penilaian terhadap penguasaan materi yang telah dipelajari. 
Untuk lebih memaksimalkan potensi siswa dalam belajar, diperlukan adanya pengendalian dan pengontrolan proses belajar melalui pemberdayaan metakognisi siswa. Metakognisi merupakan kesadaran seseorang tentang proses kognitif dan kemandiriannya untuk mencapai tujuan (Flavell dalam Lioe, Fai \& Hedberg, 2006). Oleh karena itu nampaknya penggunaan teknik metakognitif dalam model Learning Cycle 5E akan lebih memacu kemandirian belajar siswa.

Namun demikian, penggunaan model Learning Cycle $5 E$ dengan teknik metakognitif belum tentu mempunyai keefektifan yang sama jika diterapkan pada level sekolah yang berbeda. Hal ini dikarenakan level sekolah yang berbeda mempunyai rata-rata kemampuan siswa yang berbeda pula. Dengan kata lain mungkin ada interaksi antara level sekolah dan model pembelajaran (LCT) terhadap peningkatan kemandirian belajar siswa. Dugaan ini didasarkan hasil penelitian Ratnaningsih (2007) bahwa ada interaksi antara level sekolah dan model pembelajaran terhadap kemandirian belajar siswa. Selanjutnya, Yumiati (2015) menyimpulkan bahwa terdapat interaksi antara faktor pembelajaran dengan level sekolah terhadap peningkatan self regulated learning siswa. Kedua penelitian ini masingmasing menggunakan pembelajaran kontekstual dan CORE (connecting, organizing, reflecting, extending) yang merupakan pembelajaran berbasis konstruktivisme.

Penelitian ini bertujuan untuk memberikan gambaran tentang pencapaian dan peningkatan kemandirian belajar matematika pada siswa yang menggunakan model Learning Cycle $5 E$ dengan Teknik Metakognitif (LCT), Learning Cycle $5 E$ (LC), dan pembelajaran Konvensional (KV). Secara lebih khusus penelitian ini bertujuan untuk menganalisis perbedaan pencapaian dan peningkatan kemandirian belajar antara siswa yang mendapat LCT, LC, dan siswa yang mendapat $\mathrm{KV}$ baik ditinjau dari keseluruhan siswa (gabungan level sekolah tinggi dan sedang) maupun ditinjau dari level sekolah (tinggi, sedang). Selain itu penelitian ini bertujuan untuk menganalisis pengaruh interaksi antara model pembelajaran dan level sekolah terhadap peningkatan kemandirian belajar siswa. Melalui penelitian ini diharapkan akan menambah literatur tentang model pembelajaran untuk meningkatkan kemandirian belajar bagi siswa.

\section{KAJIAN LITERATUR}

\section{Kemandirian Belajar Regulated Learning)}

(Self-

Kemandirian belajar sebagai arti dari Self-Regulated Learning dijelaskan oleh wolters, Pintrich, \& Karabenick (2003) sebagai proses konstruktif dan aktif dimana siswa menentukan tujuan belajar, memonitor, mengatur, dan mengendalikan kognisi, motivasi, dan perilaku dengan dibimbing dan dibatasi oleh tujuan dan karakteristik kontekstual dalam lingkungan. Selanjutnya Zimmerman (dalam Darr \& Fisher, 2004) menjelaskan bahwa kemandirian belajar meliputi tiga tahap utama yang berulang yaitu: forethought (pikiran sebelumnya atau sesudahnya), performance control (mengontrol kinerja), dan selfreflection (refleksi diri). Forethought melibatkan menganalisis tugas dan 
mengatur tujuan yang ingin dicapai. Performance control mengacu pada memonitor dan mengontrol tindakan kognitif, sikap, emosi dan motivasi, yang mempengaruhi kinerja. Selfreflection berkaitan dengan membuat pertimbangan tentang hal yang telah dicapai dan merubah perilaku dan orientasi tujuan, apabila diperlukan. Dengan demikian kemandirian belajar merupakan proses konstruktif dan aktif yang ditandai dengan adanya penganalisisan tugas dan pengaturan tujuan yang akan dicapai, membuat strategi atau rencana untuk mencapai tujuan, melaksanakan strategi, memonitor dan melakukan pengontrolan terhadap kinerja, dan melakukan evaluasi untuk mengadakan perbaikan terhadap kelemahan kelemahan dalam rangka mencapai tujuan secara efektif dan efisien.

Sejalan dengan kedua pendapat di atas dari hasil penelitiannya, Marcou \& George (2005) menemukan bahwa kemandirian belajar secara signifikan berkaitan erat dengan self-efficacy, kepercayaan pada tugas yang bermanfaat (task-value beliefs), orientasi dari dalam diri (intrinsic goal orientation) dan orientasi dari luar (extrinsic goal orientation). Ditemukan juga bahwa semua faktor tersebut selain faktor orientasi dari luar, secara signifikan mempengaruhi kemampuan pemecahan masalah matematis.

Dari berbagai pendapat di atas dapat disimpulkan bahwa siswa yang memiliki kemandirian belajar akan menentukan tujuan belajar yang ingin dicapai, merencanakan segala keperluan atau hal-hal yang sekiranya dibutuhkan untuk belajar, memilih strategi yang tepat, melaksanakan perencanaan yang sudah dibuat, melaksanakan pemantauan atau pengontrolan diri terhadap tindakan, sikap, dan motivasi yang akan mempengaruhi kenerja dan hasil belajar, dan melakukan evaluasi terhadap capaian yang diperoleh. Evaluasi, dijadikan bahan pertimbangan untuk menentukan tindakan berikutnya. Dengan demikian segala kegiatan yang dilakukannya sudah direncanakan sehingga memungkinkan tercapainya tujuan yang ingin dicapai secara efisien dan efektif.

\section{Model Learning Cycle $5 E$ dengan Teknik Metakognitif}

Model Learning Cycle $5 E$
dengan teknik metakognitif merupakan model Learning Cycle $5 \mathrm{E}$ yang menggunakan teknik metakognitif pada setiap tahapannya. Teknik metakognitif yang digunakan berupa pertanyaan yang diajukan pada diri siswa sendiri yang difokuskan pada tiga katagori pertanyaan yang diadopsi dari Beeth (Mittlefehldt \& Grotzer, 2003). Kejelasan (intelligibility) sebagai kategori pertama, yaitu ketika siswa bertanya pada diri sendiri, "Apakah hal tersebut dapat saya mengerti?". Hal ini memberikan dasar konseptual untuk mengaktifkan proses metakognitif mereka. Penerapan yang luas (wideapplicability) sebagai kategori kedua berupa pertanyaan, "Dapatkah konsep ini digunakan pada bidang lain?". Selanjutnya masuk akal (plausibility) sebagai kategori ketiga, siswa bertanya pada diri sendiri, "Apakah saya harus percaya ide tersebut?"

Melalui pertanyaan seperti itu siswa akan selalu memantau pemikirannya, sampai sejauh mana siswa menguasai konsep atau materi 
yang diajarkan serta pengaplikasiannya dalam bidang lain. Siswa juga akan dilatih untuk berpikir mencari jalan atau alasan sebelum mempercayai ide-ide yang disampaikan orang lain.

Beberapa studi telah dilakukan terhadap penggunaan model Learning Cycle 5E, namun studi tentang penggunaan model tersebut untuk meningkatkan kemandirian belajar masih belum ditemukan. Studi tersebut diantaranya dilakukan oleh Tuna dan Kacar (2013) yang menyimpulkan bahwa rata-rata pencapaian prestasi akademik siswa pada materi Trigonometri di kelas $\mathrm{X}$ yang menggunakan Learning Cycle $5 E$ lebih tinggi daripada siswa yang menggunakan pembelajaran konvensional. Selanjutnya berbagai studi telah dilakukan terhadap pemberdayaan metakognitif siswa diantaranya oleh Camahalan (2006) dan Schraw (dalam Toit dan Kotze, 2009). Kedua hasil studi tersebut mendukung bahwa prestasi akademik ditingkatkan oleh pengaturan metakognitif siswa yang dapat memanfaatkan sumber daya dan strategi yang ada dengan baik.

\section{METODE PENELITIAN}

\section{Jenis Penelitian}

Penelitian ini merupakan penelitian kuasi eksperimen dengan menggunakan disain kelompok kontrol pretes - postes.

\section{Waktu dan Tempat Penelitian}

Penelitian ini dilakukan pada tahun pelajaran 2015/2016 di salah satu SMP level tinggi dan satu SMP level sedang yang ada di Kabupaten Indramayu. Level sekolah didasarkan pada skor akreditasi dari Badan Akreditasi Nasional.

\section{Populasi dan Sampel}

Populasi dalam penelitian ini yaitu siswa SMP di Indramayu, Jawa Barat. Sampel adalah siswa kelas VIII dari sekolah level tinggi dan sedang yang berjumlah 173 orang. Pemilihan sekolah dilakukan secara acak dari seluruh SMP di Indramayu. Dari level sekolah tinggi dan sedang yang terpilih, selanjutnya tiga kelas dipilih secara acak, masing-masing kelas berturut-turut menggunakan model LCT, LC, dan KV.

\section{Data, Instrumen, dan Teknik Pengumpulan Data}

Data yang dianalisis berupa skor dari jawaban siswa pada skala kemandirian belajar yang diberikan sebelum perlakuan/pembelajaran diberikan dan setelah semua perlakukan diberikan. Instrumen yang digunakan berupa skala kemandirian belajar dan lembar observasi. Aspekaspek kemandirian belajar yang diukur yaitu inisiatif belajar; mendiagnosis kebutuhan belajar; menetapkan tujuan belajar; mengatur dan mengontrol kinerja atau belajar; mengatur dan mengontrol kognisi, motivasi, perilaku (diri); memandang kesulitan sebagai tantangan; mencari dan memanfaatkan sumber belajar yang relevan; memilih dan menerapkan strategi belajar; mengevaluasi proses dan hasil belajar; serta self-eficacy (konsep diri).

Skala kemandirian belajar tersebut terdiri atas 42 item pernyataan dengan lima pilihan yaitu SS (sangat sering), SR (sering), KD (kadang kadang), JR (jarang), dan JS (jarang sekali). Uji coba untuk memperoleh instrumen yang valid dilakukan pada 
skala terbatas, kemudian tahap berikutnya dilakukan uji coba pada 36 orang siswa kelas VIII SMP di Indramayu. Selanjutnya pemberian skor ditentukan berdasarkan distribusi jawaban responden (Azwar, 1995).

Untuk lebih meyakinkan bahwa data yang diperoleh benar benar merupakan jawaban siswa atas kondisi yang sebenarnya maka diadakan klarifikasi melalui hasil observasi dan wawancara.

\section{Teknik Analisis Data}

Pencapaian kemandirian belajar diukur dari skor akhir siswa. Sementara itu peningkatan kemandirian dihitung dengan menggunakan formula dari Meltzer (2002).

Dalam menganalisis data, langkah pertama yaitu menguji normalitas sebaran data subyek sampel Apabila data berdistribusi normal

Tabel 1. Rekapitulasi skor kemandirian belajar siswa

\begin{tabular}{cccccc}
\hline \multirow{2}{*}{ Level sekolah } & Kel. & Jumlah siswa & \multicolumn{3}{c}{ Rata-rata } \\
& & & Skor awal & Skor akhir & Gain \\
\hline \multirow{2}{*}{ Tinggi } & LCT & 26 & 142,45 & 162,97 & 0,26 \\
& LC & 27 & 136,65 & 157,22 & 0,24 \\
& KV & 30 & 139,79 & 149,20 & 0,11 \\
\multirow{2}{*}{ Sedang } & LCT & 30 & 135,86 & 154,29 & 0,21 \\
& LC & 30 & 133,68 & 148,09 & 0,17 \\
\multirow{2}{*}{ Total } & KV & 30 & 132,92 & 141,44 & 0,10 \\
& LCT & 56 & 138,92 & 158,32 & 0,24 \\
& LC & 57 & 135,08 & 152,42 & 0,20 \\
& KV & 60 & 136,35 & 145,32 & 0,11 \\
\hline \multirow{2}{*}{} & & & & Skor maksimal ideal: 222
\end{tabular}

Dari Tabel 1 dapat kita lihat bahwa skor awal untuk setiap kelompok relatif sama. Sementara itu baik dilihat secara keseluruhan maupun pada setiap level sekolah, pencapaian dan peningkatan kemandirian kelompok digunakan ANOVA satu jalur yang dilanjutkan dengan uji Scheffe (apabila varian homogen) atau uji Dunnet (apabila varian tidak homogen). Apabila syarat normalitas distribusi data tidak terpenuhi, digunakan uji Kruskal Wallis yang dilanjutkan dengan uji Multiple Comparissons Between Treatments.

Untuk mengetahui ada tidaknya pengaruh interaksi antara model pembelajaran dan level sekolah terhadap peningkatan kemandirian belajar siswa, digunakan The Adjusted Rank Transform Test (Leys \& Schumann, 2010).

\section{HASIL PENELITIAN DAN PEMBAHASAN}

\section{Hasil penelitian}

Berdasarkan hasil perhitungan, skor kemandirian belajar siswa disajikan pada Tabel 1. 
Tabel 2. Ringkasan uji perbedaan pencapaian kemandirian belajar

\begin{tabular}{|c|c|c|c|c|c|}
\hline Level Sekolah & Kel. & Kruskal Wallis & ANOVA & Sig. & $\mathbf{H}_{\mathbf{0}}$ \\
\hline \multirow{4}{*}{ Tinggi } & LCT & & & & \\
\hline & $\mathrm{LC}$ & - & 9,77 & 0,000 & Ditolak \\
\hline & KV & & & & \\
\hline & LCT & & & & \\
\hline \multirow[t]{3}{*}{ Sedang } & LC & 8,02 & - & 0,000 & Ditolak \\
\hline & $\mathrm{KV}$ & & & & \\
\hline & LCT & & & & \\
\hline Total & $\mathrm{LC}$ & 19,29 & - & 0,000 & Ditolak \\
\hline
\end{tabular}

\begin{tabular}{lll} 
& KV & \\
\hline Berdasarkan & Tabel & 2
\end{tabular}

disimpulkan, paling sedikit satu kelompok memiliki perbedaan pencapaian kemandirian. Selanjutnya dilihat dari total siswa dengan menggunakan uji Multiple Comparissons Between Treatments dan pada sekolah level tinggi dengan uji Scheffe disimpulkan bahwa tidak terdapat perbedaan pencapaian kemandirian antara siswa yang mendapat LCT dan LC. Namun pencapaian kemandirian siswa yang mendapatkan LCT dan LC lebih baik daripada siswa yang mendapat KV.

\begin{abstract}
Sementara itu pada level sekolah sedang, dari hasil uji Multiple Comparissons Between Treatments diperoleh, tidak terdapat perbedaan pencapaian kemandirian antara siswa yang mendapat LCT dan LC dan antara siswa yang mendapat LC dan KV. Namun pencapaian kemandirian siswa yang mendapatkan LCT lebih baik daripada siswa yang mendapatkan KV.

Untuk mengetahui perbedaan peningkatan kemandirian belajar, dilakukan analisis terhadap data gain. Hasil analisis disajikan pada Tabel 3.
\end{abstract}

Tabel 3. Ringkasan uji perbedaan peningkatan kemandirian belajar

\begin{tabular}{ccccc}
\hline Level Sekolah & Kel. & Kruskal-Wallis & Sig. & $\mathbf{H}_{\mathbf{0}}$ \\
\hline \multirow{2}{*}{ Tinggi } & LCT & 36,66 & 0,000 & Ditolak \\
& LC & & & \\
& KV & & & Ditolak \\
Sedang & LCT & 21,01 & 0,000 & \\
& LC & & & Ditolak \\
& KV & & 0,000 & \\
\hline \multirow{2}{*}{ Total } & LCT & 52,18 & & \\
& LC & & & \\
& KV & &
\end{tabular}

\begin{tabular}{ll}
\hline Berdasarkan Tabel 3, paling & LCT dan LC lebih baik daripada siswa \\
sedikit satu kelompok memiliki & yang mendapat KV. Namun, \\
perbedaan peningkatan kemandirian. & peningkatan kemandirian belajar siswa \\
Selanjutnya, dari hasil uji Multiple & yang mendapatkan LC dan LCT tidak \\
Comparissons Between Treatments & berbeda secara signifikan.
\end{tabular}
ditinjau dari keseluruhan siswa, pada level sekolah tinggi dan pada level sekolah sedang peningkatan kemandirian siswa yang mendapat

Interaksi antara Pembelajaran dan Level Sekolah terhadap 
Peningkatan Kemandirian Belajar Siswa

Dari hasil pengujian dengan The Adjusted Rank Transform Test (Leys \& Schumann, 2010) diperoleh nilai $F$ $=34.07$ dengan nilai probabilitas 0,000 , artinya terdapat pengaruh interaksi antara model dan level sekolah terhadap peningkatan kemandirian belajar siswa.

\section{Pembahasan}

Berdasarkan hasil analisis data, secara keseluruhan pencapaian kemandirian belajar siswa yang mendapatkan LCT dan LC lebih baik daripada siswa yang mendapat pembelajaran KV. Namun, tidak terdapat perbedaan pencapaian kemandirian belajar antara siswa yang mendapat LCT dan LC.

Pencapaian kemandirian tersebut mendukung terhadap peningkatan kemandirian. Hal ini dapat dilihat bahwa secara keseluruhan, pada level sekolah tinggi dan level sekolah sedang, peningkatan kemandirian belajar siswa yang mendapat LCT dan LC lebih baik daripada siswa yang mendapat KV. Namun, peningkatan kemandirian belajar siswa yang mendapatkan LCT dan LC tidak berbeda secara signifikan.

Hasil penelitian tersebut disebabkan keunggulan model LC dibandingkan pembelajaran KV. Pada tahap engage siswa dipacu agar mempunyai motivasi belajar. Hal ini sejalan dengan penjelasan Bybee dkk. (2006) dan Ergin (2012) bahwa keberhasilan tahap engage ditandai dengan adanya motivasi belajar siswa. Sementara itu Schraw, dkk. (2006) menyatakan tentang tiga komponen utama dari kemandirian belajar, yaitu kognisi, metakognisi dan motivasi. Dengan demikian kemandirian sudah dibangun sejak tahap pertama pembelajaran.

Pada tahap explore siswa lebih dipacu untuk berpikir, mengamati, dan bekerjasama untuk melakukan penyelidikan dan berlatih untuk memahami pikiran siswa lain. Pada tahap explain siswa menjelaskan hasil penemuannya di depan kelas. Pada tahap elaborate siswa dilatih untuk menyelesaikan masalah. Kegiatan pada tahap-tahap tersebut akan menjadikan siswa mandiri seperti yang dijelaskan oleh Darr \& Fisher (2004) agar siswa mandiri, siswa perlu diberi kesempatan berpikir, mengamati, dan mengikuti pikiran orang lain.

\section{Kemandirian} juga dikembangkan melalui tahap evaluate. Evaluasi tersebut direalisasikan berulang kali setiap guru dan siswa mencoba untuk mengontrol perkembangan pencapaian ke pemahaman baru. Dengan demikian penilaian dilakukan secara periodik. Menurut Paris \& Winograd (2004) menilai diri secara periodik akan bermanfaat bagi guru dan siswa, karena merupakan refleksi pada pembelajaran yang dinamik. Refleksi merupakan tahapan utama kemandirian seperti yang diungkapkan Zimmerman (dalam Darr \& Fisher, 2004)

Sementara itu LCT mempunyai kelebihan lain dalam memberdayakan metakognisi siswa dibandingkan dengan LC. Melalui teknik metakognitif siswa akan terlatih untuk mengatur dan mengontrol kinerja, dan mengevaluasi proses dan hasil belajar. Namun demikian dilihat dari siswa secara keseluruhan, baik peningkatan 
maupun pencapaian kemandirian kelompok LCT dan LC tidak berbeda secara signifikan dalam taraf signifikansi 0,05 . Hal ini karena hanya beberapa indikator saja yang mengalami peningkatan skor dari skor awal. Jika dilihat dari rata-rata skor akhir, kelompok LCT memperoleh 158,32 dan kelompok LC memperoleh 152,42 dengan rata-rata Gain untuk kelompok LCT sebesar 0,24 dan kelompok LC sebesar 0,20. Dari besarnya skor terlihat adanya skor pencapaian dan peningkatan kelompok LCT lebih tinggi dari kelompok LC, meskipun ternyata perbedaan tersebut tidak signifikan.

Pada kelas kontrol dengan pembelajaran konvensional Guru memberikan konsep secara langsung, kemudian siswa mengerjakan latihan soal. Interaksi antara siswa hanyalah terbatas pada teman satu bangku saja. Kondisi inilah yang mengindikasikan peningkatan kemandirian siswa yang mendapat LCT dan LC lebih baik dari siswa yang mendapat pembelajaran konvensional.

Hasil lain dari penelitian ini yaitu bahwa terdapat pengaruh interaksi antara model dan level sekolah terhadap peningkatan kemandirian belajar siswa. Artinya secara bersama sama model pembelajaran dan level sekolah mempengaruhi peningkatan kemandirian belajar siswa. Hasil ini sejalan dengan hasil penelitian Ratnaningsih (2007) dan Yumiati (2015) bahwa terdapat interaksi antara model dan level sekolah terhadap kemandirian belajar iswa.

Temuan ini sejalan pula dengan temuan-temuan sebelumnya diantaranya Gandhi \& Varma (2010), melalui pembelajaran metakognitif, keyakinan akan motivasi, serta pendekatan kemandirian tersebut berhasil meningkatkan kemandirian belajar matematika siswa. Yumiati (2015), bahwa pencapaian dan peningkatan SRL siswa kelompok pembelajaran CORE lebih baik daripada siswa kelompok pembelajaran konvensional ditinjau dari keseluruhan kelas, dan pada siswa level sekolah tinggi.

\section{SIMPULAN DAN SARAN}

\section{Simpulan}

Berdasarkan hasil penelitian diperoleh kesimpulan sebagai berikut:

1. Secara keseluruhan, tidak terdapat perbedaan pencapaian dan peningkatan kemandirian belajar antara siswa yang mendapat LCT dan LC. Namun pencapaian dan peningkatan kemandirian belajar siswa yang mendapatkan LCT dan LC lebih baik daripada siswa yang mendapat KV.

2. Pada level sekolah tinggi tidak terdapat perbedaan pencapaian kemandirian antara siswa yang mendapat LCT dan LC. Namun pencapaian kemandirian siswa yang mendapatkan LCT dan LC lebih baik dari siswa yang mendapat KV. Pada level sedang, tidak terdapat perbedaan pencapaian kemandirian antara siswa yang mendapat LCT dan LC dan antara siswa yang mendapat LC dan KV. Namun pencapaian kemandirian siswa yang mendapatkan LCT lebih baik dari siswa yang mendapatkan KV.

3. Pada level tinggi dan sedang, peningkatan kemandirian belajar siswa yang mendapat LCT dan LC lebih baik dari siswa yang 
mendapat KV. Namun, peningkatan kemandirian belajar siswa yang mendapatkan LC dan LCT tidak berbeda secara signifikan.

4. Terdapat pengaruh interaksi antara model pembelajaran dan level sekolah terhadap peningkatan kemandirian belajar siswa.

\section{Saran}

Berdasarkan hasil penelitian
direkomendasikan beberapa hal
sebagai berikut:

1. Model LCT dapat digunakan sebagai salah satu pembelajaran untuk meningkatkan kemandirian belajar siswa pada level sekolah tinggi dan sedang.

2. Pada saat diskusi kelompok untuk kelas yang heterogen kemampuan akademiknya maka pembentukan kelompok hendaknya dilakukan secara heterogen yaitu terdiri dari siswa kemampuan tinggi, sedang, dan rendah.

3. Karena secara keseluruhan tidak terdapat perbedaan pencapaian dan peningkatan pada taraf signifikansi 0,05 antara kelompok LCT dan LC maka diperlukan analisis lebih lanjut terhadap penyebabnya.

4. Bagi pemerhati pendidikan atau pembuat kebijakan model LCT dapat digunakan untuk mangadakan inovasi dalam pembelajaran matematika.

\section{DAFTAR PUSTAKA}

Azwar, S. (2007). Sikap Manusia (Teori dan Pengukurannya). Yogyakarta: Pustaka Pelajar.
Bybee, R.W., Taylor, J. A., Gardner, A., Scotter P.V., Powel, J.C., Westbrook, A., \& Landes, N. (2006). The BSCS $5 E$ instructional model Origins and effectiveness. Diakses tanggal 2 September 2014 dari http://bscs.org/sites/default/files/ legacy/BSCS_5E_Instructional_ Model-Full_Report.pdf.

Camahalan, F. M. G. (2006). Effects of self regulated learning on Mathematics achievement on selected Southeast Asian children. Journal of Instructional Psychology, 33(3), 194-205.

Darr, C \& Fisher, J. (2004). Selfregulated learning in Mathematics class. Diakses tanggal 2 April 2015 dari www.arb.nzcer.org.nz/nzcer3/rese arch/Maths/ 2004SRL thinkingmodels.htm.

Ergin, I. (2012). Constructivist approach based 5E model and usability instructional physics. Latin-American Journal of Physics Education, 6(1), 14 - 20. Diakses tangga 2 September 2014 dari http://www.lajpe.org

Gandhi H. \& Varma, M. (2010).

Strategic content learning approach to promote selfregulated learning in mathematics. Poceedings of epiSTME 3. 119124 diakses tanggal 7 Juni 2016 dari

http://cvs.gnowledge.org/episteme 3/ propdfs/19- haneet-verma.pdf

Hargis, J. (2000). The self-regulated learner advantage:learning science on the internet. Electronic Journal of science education, 4(4).

Diakses tanggal 8 Mei 2016 dari http://ejse.southwestern.edu/articl e/view/7637/ 5404. 
Leys, C. \& Schumann, S. (2010). A nonparametric method to analyze interactions: The adjusted rank transform test. Journal of Experimental Social Psychology, 46(4), 587-700.

Lioe, L.T, Fai, H.K. \& Hedberg, J.G. (2006). Students'metacognitive problem solving strategies in solving open-ended problems in pairs. Diakses tanggal 2 Mei 2016 dari http://conference.nie.edu.sg/paper /new converted/aboo 287.pdf.

Marcou A. \& George P. (2005). Motivational beliefs, selfregulated learning and mathematical problem solving. Proceedings of the 29th Conference of the International Group for the Psychology of Mathematics Education, 297-304.

Meltzer, D.E. (2002). The relationship between mathematics preparation and conceptual learning gains in physics: a posible "hidden variable" in diagnostic pretest scores. American Journal of Physics, 70(12), 1259-1268.

Mittlefehldt, S \& Grotzer, T. (2003). Using metacognition to facilitate the transfer of causal models in learning density and pressure. Presented at the National Association of Research in Science Teaching (NARST) Conference Philadelphia. Diakses tanggal 5 Juni 2016 dari ftp://202.83.110.129/Volume_1/fr om\%202TB/FAC\%20FOUND\%2 0STUDIES/FYLHR9 3/Subject\% 20Components/Grey\%20matters/ R54ZK1 G/Project\%20Zero/ww w.pz.harvard.edu/Research/UCPp apers/P2NARST03.pdf.
Munandar, U. (2012). Pengembangan kreativitas anak berbakat. Jakarta: PT Rineka Cipta.

Paris, S. G. \& Winograd, P. (2004). The role of self-regulated learning in contextual teaching: Principles and practices for teacher preparation $^{1[1]}$. Diakses tanggal 3 Juni 2016 dari http://www.ciera.org/library/archi ve/200104/ 0104parwin.htm

Ratnaningsih, N. (2007). Pengaruh pembelajaran Konstektual terhadap kemampuan berpikir kritis dan kreatif matematik serta kemandirian belajar siswa sekolah menengah atas. (Disertasi). Sekolah Pascasarjana, Universitas Pendidikan Indonesia, Bandung.

Runisah. (2015). Kajian kemandirian belajar dalam Matematika siswa SMP di Kabupaten Indramayu. Laporan hasil penelitian. Indramayu: Universitas Wiralodra. Schraw, G., Crippen, K.J, \& Hartley, K. (2006). Promoting selfregulation in Science education: Metacognition as part of a broader perspective on learning. Research in Science Education, 36(1), 111139.

Toit, S.D., \& Kotze, G. (2009). Metacognitive strategies in the teaching and learning of Mathematics. Pythagoras, 70, 5767. Diakses tanggal 2 Mei 2016 dari

www.pythagoras.org.za/index.php /pythagoras/article/download/39/3 $\underline{0}$

Tuna, A \& Kacar, A. (2013). The effect of 5E Learning Cycle model in teaching Trigonometry on students' academic achievement and the permanence of their knowledge. International Journal on New Trends in 
Education and Their Implications, 4(1), 73-87.

Wolters, C. A., Pintrich. P.R., \& Karabenick, S.A. (2003). Assessing academic self-regulated learning. Diakses tanggal 2 Mei 2016 dari http://www.childtrends.org/wpcontent/uploads/2013/05/ Child_Trends2003_03_12_PD_P DConfWPK.pdf

Yumiati. (2015). Meningkatkan kemampuan berpikir aljabar, berpikir kritis matematis, dan self-regulated learning siswa SMP melalui pembelajaran CORE (connecting, organizing, reflecting, extending). (Disertasi). Sekolah Pascasarjana, Universitas Pendidikan Indonesia, Bandung. 